\title{
Detection of Cassava Leaves in Multi-Temporally Acquired Digital Images of a Cassava Field Under Different Brightness Levels by Simultaneous Binarization of the Images Based on Indices of Redness/Greenness
}

\author{
Mallika Srisutham ${ }^{1,2}$, Ryoichi Doi ${ }^{1}$, Anan Polthanee ${ }^{2} \&$ Masaru Mizoguchi ${ }^{1}$ \\ ${ }^{1}$ Department of Global Agricultural Sciences, Graduate School of Agricultural and Life Sciences, The \\ University of Tokyo, Tokyo, Japan \\ ${ }^{2}$ Faculty of Agriculture, Khon Kaen University, Khon Kaen, Thailand \\ Correspondence: Ryoichi Doi, Graduate School of Agricultural and Life Sciences, The University of Tokyo, \\ Tokyo 113-8657, Japan. Tel: 81-358-415-022.E-mail: roird2000@yahoo.com/roird@aeiou.pt
}

\author{
Received: May 17, $2014 \quad$ Accepted: June 17, $2014 \quad$ Online Published: August 16, 2014 \\ doi:10.5539/mas.v8n5p87 URL: http://dx.doi.org/10.5539/mas.v8n5p87
}

The research is financed by the Japan Society for the Promotion of Science (grant-in-aid 23255014).

\begin{abstract}
Plant leaf area reveals various types of abnormalities which can enable appropriate plant/crop management actions. The quantification of plant leaf area is now feasible using commonly available digital photographing tools. Changes in brightness, however, make it difficult to compare leaf areas in digital photographs acquired at multiple time points. This difficulty could be overcome by employing an index of redness/greenness (R/G), which was suggested to be one of the best indices to discriminate between plant leaves and other objects such as soils. R/G and other indices were examined when discriminating cassava leaves from other objects in a field. A surveillance camera captured digital photographs on a daily basis. Of these, 183 photographs were stored. They were pasted into a single image file and simultaneously analyzed. The International Commission on Illumination color model's $a^{*}$ was the best index in the discrimination, with a distinctiveness score of 1.36 . R/G was the second best, with a distinctiveness score of 0.70 . The percentage of leaf-likely pixels followed sigmoidal patterns with time, resulting in great coefficients of determination of $0.981\left(a^{*}\right)$ and $0.965(\mathrm{R} / \mathrm{G})$. The percentage of leaf-likely pixels and cassava leaf weight had a real-time response relationship. The range of the $95 \%$ confidence limit was narrowed from -16 to $+14 \%$ of a predicted value of $98 \%$ leaf-likely pixels for $\mathrm{R} / \mathrm{G}$ to $\pm 12 \%$ for $a^{*}$. Thus, the simultaneous binarization and the detection of leaf-likely pixels in the photographs acquired under different brightness levels was enabled with improved discrimination accuracy by employing $a^{*}$.
\end{abstract}

Keywords: Manihot esculenta, red-green-blue and $L^{*} a * b^{*}$ color models, remote sensing, surveillance camera, temporal variation of brightness

\section{Introduction}

Plant leaf area indicates crop nutrient availability (Uhart \& Andrade, 1995; Heege, Reusch, \& Thiessen, 2008) drought stress (Alves \& Setter, 2000), physical damage of canopy (Olthof, King, \& Lautenschlager, 2003), land degradation/rehabilitation (Doi \& Ranamukhaarachchi, 2013), and other factors. As such, the consecutive observation of leaf area is an effective measure that can be employed to find abnormalities in plant growth within a certain period. For leaf area quantification of crops and other plant species, discriminating plant leaves from other objects is essential but difficult. Some indices such as the green normalized difference vegetation index (Gitelson, Kaufman, \& Merzlyak, 1996) have been developed to discriminate between leaves and other objects from earth observation satellites. Meanwhile, on the ground, Zheng, Shi, \& Zhang (2010) succeeded in discriminating between vegetable leaves and soils photographed by a commonly available digital camera. However, the discrimination may be significantly hampered by changes in brightness (Pettorelli, 2013). Thus, because of temporal changes in brightness, the consecutive discrimination between leaves and other objects has 
proven difficult.

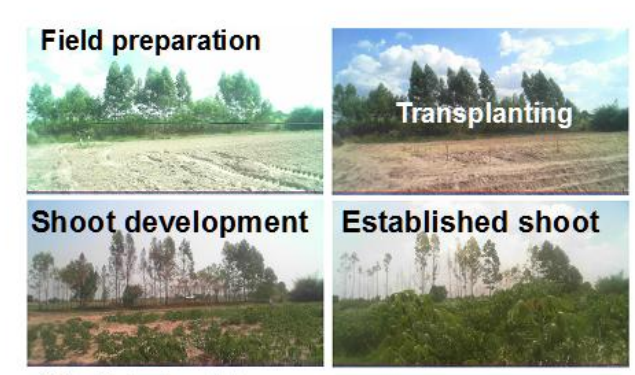

(1) Original images

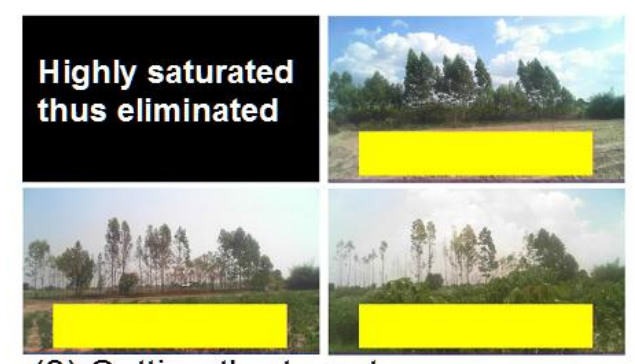

(3) Setting the target area

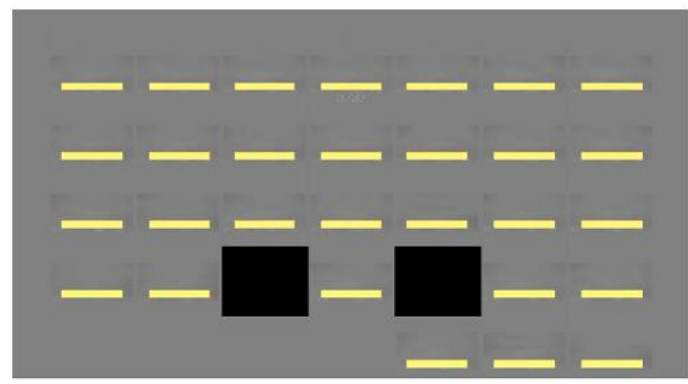

(5) Reading grayscale intensity values for all target areas generated in the study period to obtain grayscale intensity distribution diagrams for R / $G$ and others

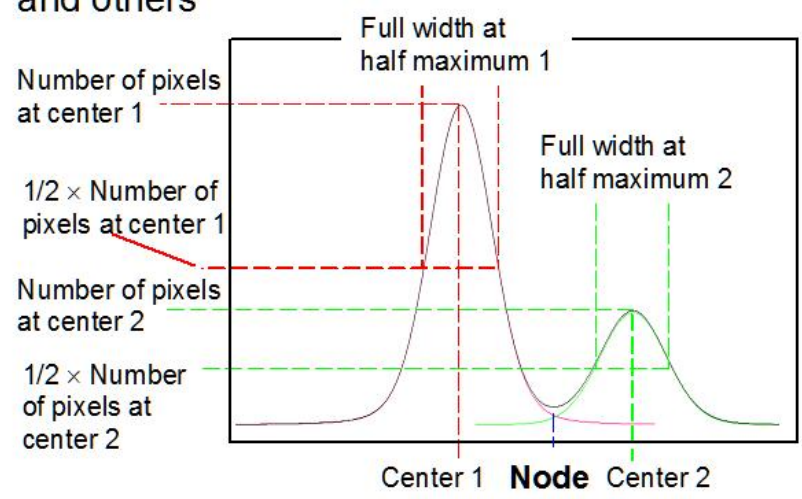

(6) Determining the node for binarization

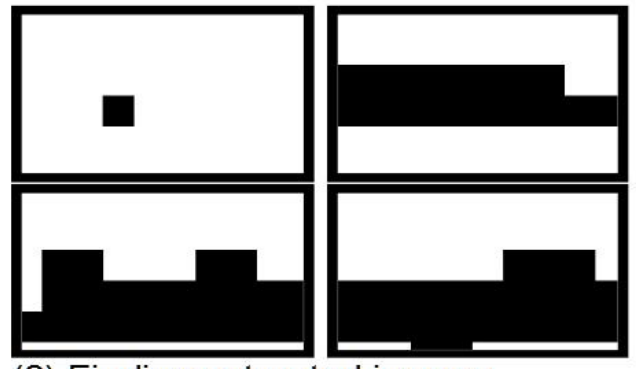

(2) Finding saturated images

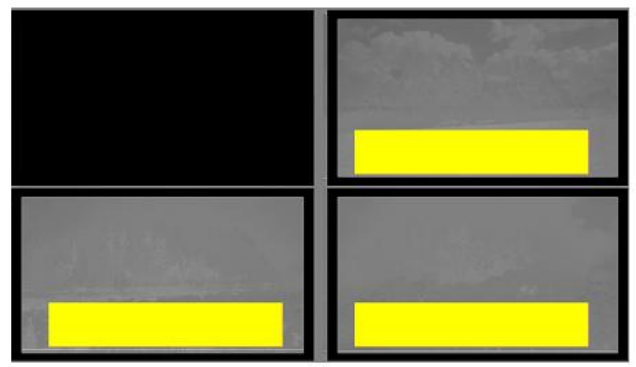

(4) Preparing grayscale images

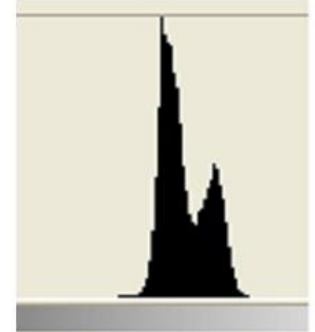

$\mathrm{R} / \mathrm{B}$ or another parameter

Fig. 1. Procedures of image processing for discriminating between cassava leaves and other objects in the current field in Khon Kaen province, Thailand

Among the various indices to discriminate between leaves and other objects, redness/greenness (R/G) was demonstrated to be one of the best (Yang, Willis, \& Mueller, 2008). Although soil colors can vary, most plant leaves are greenish. Greenish soils and other non-leaf objects are very rare. In this context, when discriminating 
between leaves and other objects, $\mathrm{R} / \mathrm{G}$ must be favored. Despite this, $\mathrm{R} / \mathrm{G}$ has been used very rarely in the discrimination of plant leaves and other objects (Yang, Willis, \& Mueller, 2008, Doi, Arif, Setiawan, \& Mizoguchi, 2013). The most likely reason for this is that data on R/G do not include those on other spectra that help in the detection/observation of areas other than agricultural fields. On the other hand, in agricultural fields, the distribution patterns of objects are simpler. Soil and plant shoots comprise the majority and the number of other objects is negligible. Hence, $\mathrm{R} / \mathrm{G}$ was considered to be sufficiently useful for the discrimination between leaves and other objects in agricultural fields. Furthermore, today, data on R/G in an area is quite easily attained through digital photography and digital image processing. The index does not require complicated calculation procedures that rely on sophisticated and expensive sensors and other equipment. Therefore, the index is widely available.

The index is expected to be less affected by changes in brightness than some other indices (Pettorelli, 2013). In multi-temporally acquired digital images, redness and greenness have significant correlations with brightness. Redness, greenness, and brightness in multi-temporally acquired images change proportionally (Doi, 2012). Thus, $\mathrm{R} / \mathrm{G}$ could be an index to discriminate between leaves and other objects. The proportionality must compensate for the disadvantage (Yang, Willis, \& Mueller, 2008), i.e., the index must involve no infrared reflectance, which is helpful in finding leaves (Jordan, 1969). In addition, in the brightness adjustment of the green and red intensity values of the entire area of a single color digital photograph, each of the green and red grayscale images is individually brightness-adjusted and then combined to prepare a red and green intensity-adjusted color digital image (Doi, 2014). This laborious brightness adjustment of multiple digital photographs could be skipped if R/G was used because of the proportionality among $R, G$, and brightness. Discrimination between plant leaves and other objects could be possible through the chronological placement of color digital photographs of a target photographed area and the simultaneous binarization of all pixels in the target areas to visualize pixels that represent the leaves.

In this study, the applicability of $\mathrm{R} / \mathrm{G}$ in discriminating between cassava leaves and other objects was evaluated. Cassava cuttings were planted in a field in Thailand. The field was digitally photographed daily. The digital images were pasted into a single digital image, and the best $\mathrm{R} / \mathrm{G}$ value for discriminating between the leaves and other objects was statistically determined. The discriminatory power was evaluated by determining the fitness of the increase in leaf-likely pixels to a sigmoidal curve as the typical pattern of increase in cassava leaf biomass (Alves \& Setter, 2004). Also, the authors examined greenness per luminosity when luminosity was given as a measure of brightness. Likewise, yellowness (redness + greenness)/luminosity was used because of its consistency as well as change in brightness (Doi, 2012; Doi, 2014). The International Commission on Illumination color model's $a^{*}$ (Adobe Systems, 2002) was also investigated as another index of R/G.

\section{Methods}

\subsection{Site Description}

The field was located in Khon Kaen city, Khon Kaen province, Thailand ( $16^{\circ} 34^{\prime} 11^{\prime \prime}$ N, $102^{\circ} 40^{\prime} 78^{\prime \prime}$ E). In Khon Kaen, the mean annual temperature is $27^{\circ} \mathrm{C}$, and the annual precipitation is $1,248 \mathrm{~mm}$. The climate is classified as savanna according to Köppen (1931).

Two cultivars of cassava (Manihot esculenta), KU 50 and Rayong 11, were planted on 26 November 2012. Cassava cuttings, 15 to $20 \mathrm{~cm}$ in length, were planted at $60 \mathrm{~cm} \times 100 \mathrm{~cm}$ spacing. No irrigation water was available, and the growth was thus dependent on precipitation and soil moisture.

\subsection{Digital Photography and Handling Digital Photographs}

In this study, digital photographs of a cassava field were used. The photographs were captured by a surveillance camera, UCAM-DLO130, Elecom Co., Ltd., Osaka, Japan. The digital photographs were captured daily between 12:00 and 12:30, and stored on a hard disk between 26 November 2012 and 31 May 2013. The number of pixels in the field photograph was 8712. One hundred and eighty-three digital photographs were acquired. When the photograph was captured, the data on the values of the red-green-blue (RGB) color intensity were generated. The Adobe RGB 1998 color space was chosen as one of the RGB color spaces (Adobe Systems, 2002). Some extremely bright/saturated photographs were generated possibly due to computer software glitches. These saturated photographs were eliminated by adopting the following criteria (Figure 1) using Adobe Photoshop 7.0 as one of the tools for digital image processing. A luminosity grayscale image to indicate the brightness of each pixel was obtained as described later. In the luminosity grayscale image, 1089 pixels were merged. Then, the mean brightness for the pixels was determined. A luminosity value of 200 was used as the threshold to find dark-enough merged pixels. When only a single pixel or no merged pixels were darker than the luminosity value of 200 , the original photograph was regarded to be highly saturated and eliminated in the 
following processes. Forty-five photographs were eliminated and the remaining 138 photographs were used.

The 138 RGB color digital photographs were pasted into a new file window of Adobe Photoshop 7.0. In the photograph of each day, in another layer overlapping the file window, a target area was set on the area that included the cassava cuttings and soil (Figure 1). The number of analyzed pixels in the target area was 1350 . Using Adobe Photoshop 7.0, the grayscale images that show the intensity values of $R$, G, and B, and the value of $a^{*}$ were prepared (Doi, 2013). The $\mathrm{R}+\mathrm{G}$ (RGB yellow) grayscale image was prepared by merging the $\mathrm{R}$ and $\mathrm{G}$ grayscale images at the same weight (Doi, 2014). The luminosity grayscale image was prepared by merging the $\mathrm{R}, \mathrm{G}$, and $\mathrm{B}$ grayscale images at weights of $0.51,1.00$, and 0.19 , respectively (Handschuh, Schwaha, \& Metscher, 2010). These grayscale images were further used to prepare those that show the values of G/luminosity, $(\mathrm{R}+\mathrm{G}) /$ luminosity, and R/G.

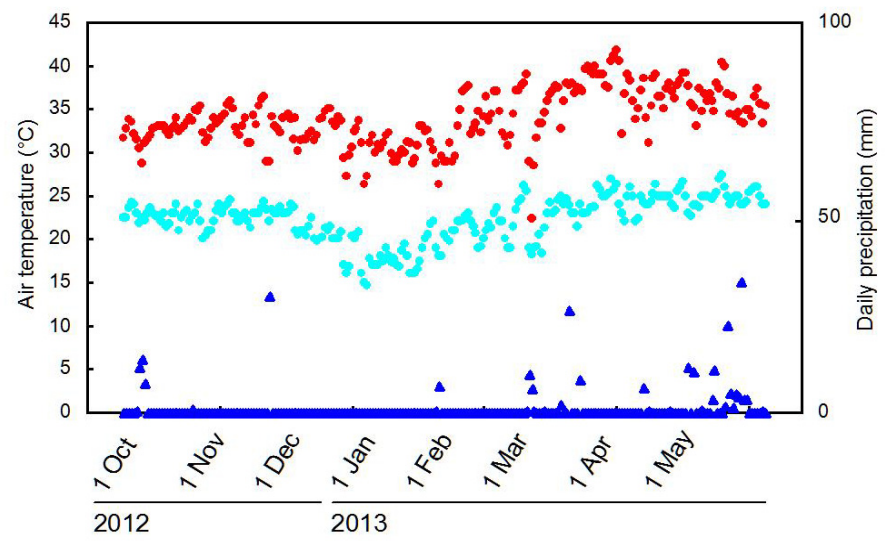

Fig. 2. Meteorological conditions of the region in the study period The symbols indicate the maximum daily temperature $(\bullet)$, the minimum daily temperature (•), and daily precipitation ( $\mathbf{\Delta})$.

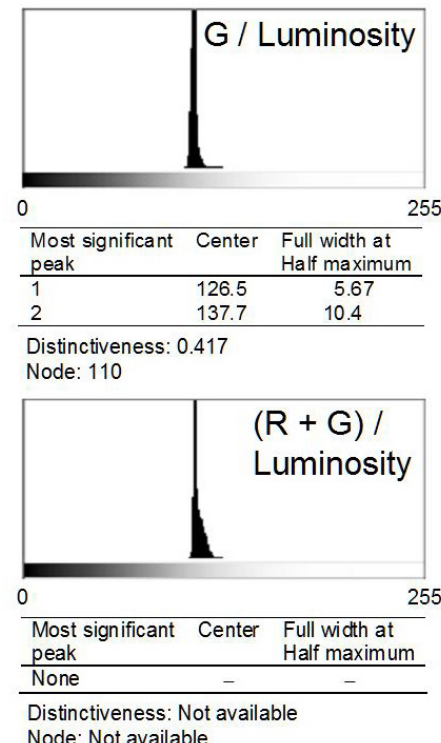

Node: Not available

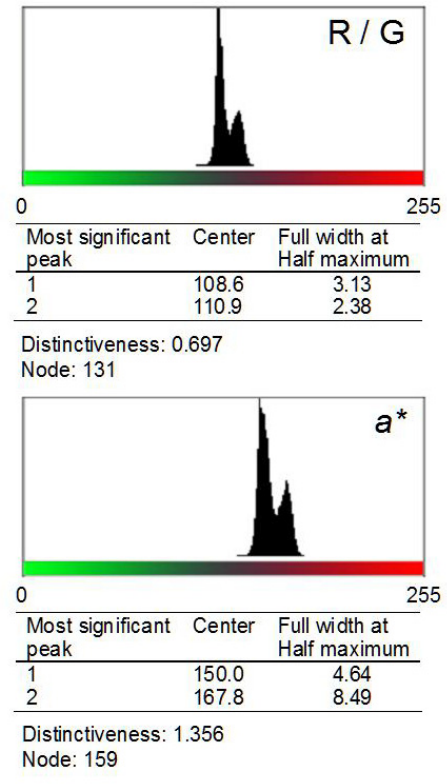

Fig. 3. Distribution patterns of the intensity values of grayscale of $\mathrm{G} /$ luminosity and other color indices in the target areas in the grayscale images derived from the 138 digital photographs captured in the period of this study 


\subsection{Statistical Performance}

To find the threshold value of grayscale intensity to discriminate between leaves and other things such as soil in the target area, all 138 target areas were analyzed simultaneously (Figure 1). In the target frames in each grayscale image, the intensity values of $\mathrm{G} /$ luminosity, $(\mathrm{R}+\mathrm{G}) / \mathrm{luminosity}, \mathrm{R} / \mathrm{G}$, or $a^{*}$ were read for the 186,300 pixels ( $=138$ target areas $\times 1350$ pixels/target area). A diagram was prepared to show the distribution pattern of the grayscale intensity values for the 186,300 pixels. The intensity values were provided as digital numbers between 0 and 255. The most significant two peaks were regarded to represent the leaf and other pixels. Then, the value as the node to separate the two peaks was statistically determined using Fityk 0.8.0 (Marcin Wojdyr) as a tool for peak separation. The distinctiveness in the separation was determined using the following equation (Figure 1):

$$
\text { Distinctiveness }=\mid \text { Center of peak } 1-\text { Center of peak } 2||
$$

(Full width at half maximum of peak $1+$ Full width at half maximum of peak 2)

The value of the node was used to generate binary images to discriminate between the leaves and other objects in the target area. After the binarization, leaf-likely pixels were shown as black pixels. The percentage of leaf-likely pixels in the target area was determined using Adobe Photoshop 7.0.

Using the statistical software SPSS 10.0.1 (SPSS Inc.), a sigmoidal relationship between the percentage of leaf-likely pixels and the number of days after transplanting the cassava cuttings was examined.

\section{Results}

The closest weather station of Khon Kaen reported the amount of precipitation within the study period to be 186 $\mathrm{mm}$, and the air temperature ranged between 14.7 (1 January 2013) and $41.8^{\circ} \mathrm{C}$ (5 April 2013, Figure 2). During the period of this study, the mean air temperature was $28.4^{\circ} \mathrm{C}$.

Figure 3 shows the distribution patterns of the grayscale intensity values between 0 and 255 in the 138 target frames. Values of R/G and $a^{*}$ were converted to those between green (0) and red (255). According to the values of distinctiveness, among the indices, $a^{*}$ most distinctively separated the two most significant peaks on the scale. $\mathrm{R} / \mathrm{G}$ was the second best for separating the primary two peaks. The comparative relationships among the indices were also visually perceivable. The diagram for $a^{*}$ or R/G indicates two main peaks but those for $\mathrm{G} /$ luminosity and $(\mathrm{R}+\mathrm{G}) /$ luminosity did not show clear multiple peaks.

Given these results, the values of the node for $\mathrm{R} / \mathrm{G}$ and $a^{*}$ were used in the following processes. After eliminating saturated photographs, the target area was binarized by adopting the node value (Figure 3 ) as the threshold of the grayscale intensity (Figure 1). Pattern increases in leaf-likely pixels were examined if they followed sigmoidal patterns with time (Gray, 2000). The authors found sigmoidal patterns in the increase of leaf-likely pixels for $\mathrm{R} / \mathrm{G}$ and $a^{*}$ (Figure 4). The great values of the coefficient of determination $\left(\mathrm{R}^{2}>0.964\right)$ demonstrate the relevance of the leaf-likeliness of the black pixels generated by the binarization (Figure 1). The fitness was better $\left(\mathrm{R}^{2}=0.981\right)$ for $a^{*}$ than $\mathrm{R} / \mathrm{G}\left(\mathrm{R}^{2}=0.965\right)$. This relationship was also visually recognized as a smaller delineation of outliers from the predicted values for the $a^{*}$ diagram (Figure 4). The lower and upper 95\% confidence limits were $-16 \%$ and $+14 \%$ of a predicted value of $98 \%$ leaf-likely pixels in May 2013, respectively, for $\mathrm{R} / \mathrm{G}$, while the values were improved to be $\pm 12 \%$ for $a^{*}$ (Figure 4 ).

Relationships between the increases in leaf-likely pixels in the target area and cassava growth are shown in Figure 5. Leaf-likely pixels (\%) in the target area did not respond quickly to the increases in cassava height (Figure 5a). On the other hand, the increase in leaf-likely pixels and that in cassava leaf fresh weight showed a real-time relationship until the target area was filled with leaf-likely pixels between 13 March and 13 April (Figure 5b). 


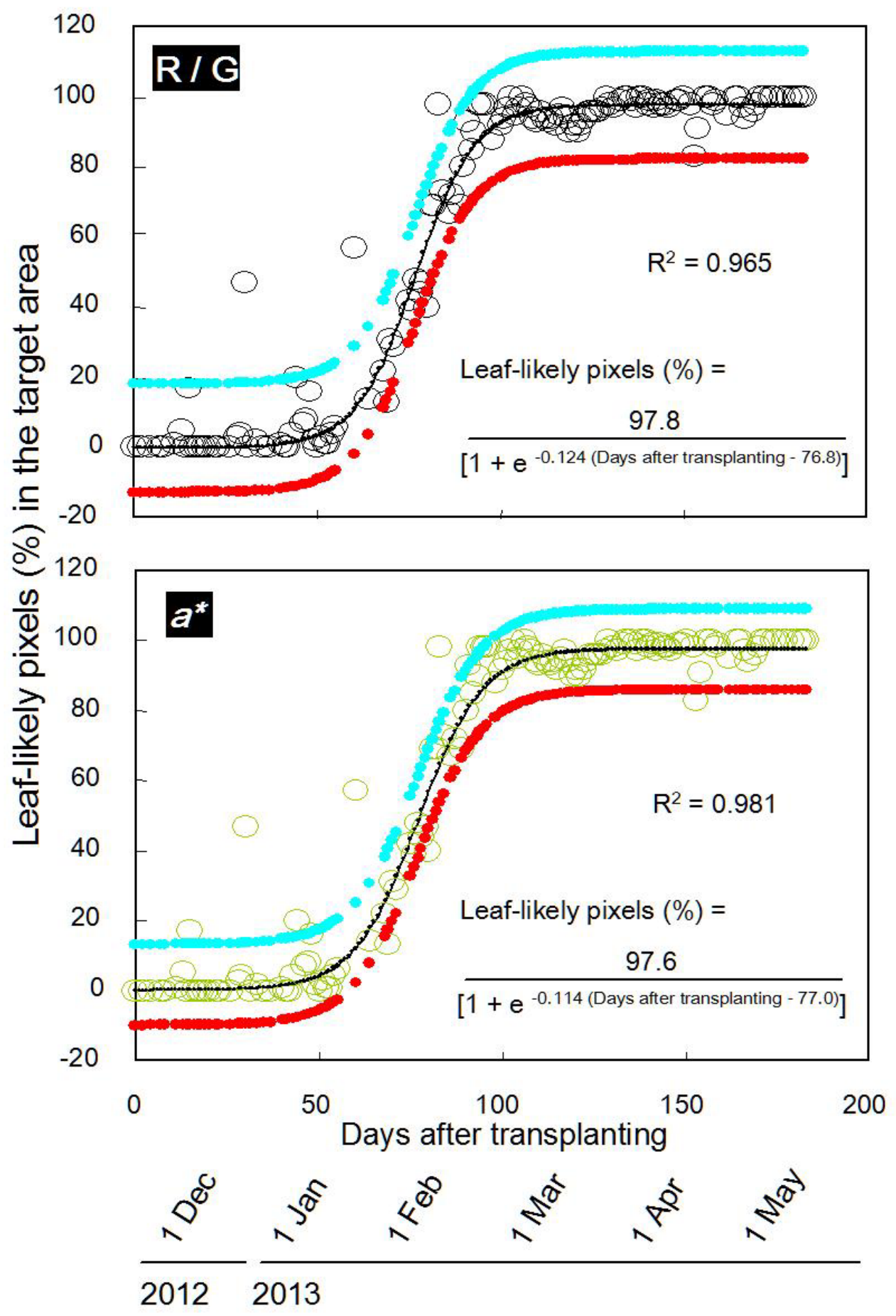

Fig. 4. Changes in leaf-likely pixels' percentage for the target area based on the R/ G (top) and the $a^{*}$ (bottom) grayscale images. The symbols indicate observed ( $\circ$ R / G; $\circ a^{*}$ ) and predicted ( - ) values, respectively. The light blue (*) and the red $(\bullet)$ dots indicate upper and lower $95 \%$ confidence limits, respectively. 


\section{Discussion}

The study period was meteorologically characterized according to the aridity index (de Martonne, 1926). For the study period, the value was 4.84 (= $186 /[28.4+10])$, comparable to values of the arid lands. Because of the hot and dry weather, however, the cassava seedlings grew by relying on soil moisture stored in the previous months during the rainy season (Doi \& Ranamukhaarachchi, 2009a).

In this study, the relative superiority of $\mathrm{R} / \mathrm{G}$ and $a^{*}$ compared to others in the discrimination between the cassava leaves and other objects was shown. The superiority is based on their ranges in a color space. $\mathrm{G} /$ luminosity or $(\mathrm{R}+\mathrm{G}) /$ luminosity describes colors between black (grayscale value $=0$ ) and the most colorful green or RGB yellow (grayscale value $=255$ ). On the other hand, $\mathrm{R} / \mathrm{G}$ or $b^{*}$ shows colors between the most colorful red and green via gray (Moriizumi, Nakashima, Okumura, \& Yamanoi, 2009), at which the intensity values of red and green are the same (Figure 3) (Lakio, Heinamaki, \& Yliruusi, 2010). This nature of R/G and $a^{*}$ is advantageous to discriminate between greenish and reddish objects. Both the intensity values of $\mathrm{R}$ and $\mathrm{G}$ are affected by brightness and, as such, normalization is required to compare the information carried by digital photographs acquired over a period of time. However, for R/G, the effects of brightness changes in the study period were minimized because the intensity values of $R$ and $G$ change proportionally with that of luminosity as a parameter of brightness (Doi, 2012). Likewise, $a^{*}$, which has a close relationship with $\mathrm{R} / \mathrm{G}$, showed great consistency in discriminating between the leaves and other objects. Thus the color component $a^{*}$ was found to be another feasible index for discriminating between leaves and other objects in digital photographs.

When changes in the percentage of leaf-likely pixels in the $\mathrm{R} / \mathrm{G}$ and $a^{*}$ grayscale images were compared (Figure $4)$, a significant correlation was found $\left(\mathrm{R}^{2}=0.996, P<0.001\right)$. This high correlation supports the hypothesis that $a^{*}$, as an index of redness/greenness, consistently showed differences between the leaves and other objects within the conditions in this study. Half of the target area was occupied by leaf-likely pixels 77 days after transplanting (Doi \& Ranamukhaarachchi, 2009b) (Figure 4). The time point was mid-February when rapid increases in leaf-likely pixels were indicated. The smooth sigmoidal curves with high $\mathrm{R}^{2}$ values indicate that the binarized black and white pixels in the target areas were very likely to represent the cassava leaves and other objects, respectively.

The delayed increase in the percentage of leaf-likely pixels in the target areas compared with the increase in cassava height (Figure 5a) means that the cassava cuttings gained height before expanding their leaves. This time lag was possibly caused by the dryness of the upper layer of soil in which the cassava cuttings were developing roots, which later went down to much moister layers (Alves \& Setter, 2004). On the other hand, the real-time response of the percentage of leaf-likely pixels to mean cassava leaf fresh weight (Figure 5) again indicates the leaf-likeliness of the black pixels in the binarized target areas (Figure 1).

A profitable finding of this study was that the color component $a^{*}$, in addition to $\mathrm{R} / \mathrm{G}$, consistently indicated leaf-likely pixels by adopting the node value despite brightness changes in the study period (Figure 4). Furthermore, $a^{*}$ was better than $\mathrm{R} / \mathrm{G}$ in the discrimination between cassava leaves and other objects in the field (Figures 3,4). The International Commission on Illumination's $L^{*} a^{*} b^{*}$ color model can describe all visible colors. Meanwhile, the color space of the current RGB color model is included in the $L^{*} a^{*} b^{*}$ color gamut (Adobe Systems, 2002). In the RGB color model, the darkest and the most colorful red or green colors are described by the intensity values of 0 and 255, respectively. These extreme RGB colors are still those in between 0 and 255 in the $L^{*} a^{*} b^{*}$ description. The most colorful RGB green $(\mathrm{G}=255)$ has an $a^{*}$ value of 49 , whereas the most colorful RGB red $(\mathrm{R}=255)$ has an $a^{*}$ value of 209 when all visible colors have values of $a^{*}$ between 0 and 255. This nature of the $L^{*} a * b^{*}$ color model which describes all visible colors was thought to be the advantage that enhanced the discrimination between the cassava leaves and other objects. 


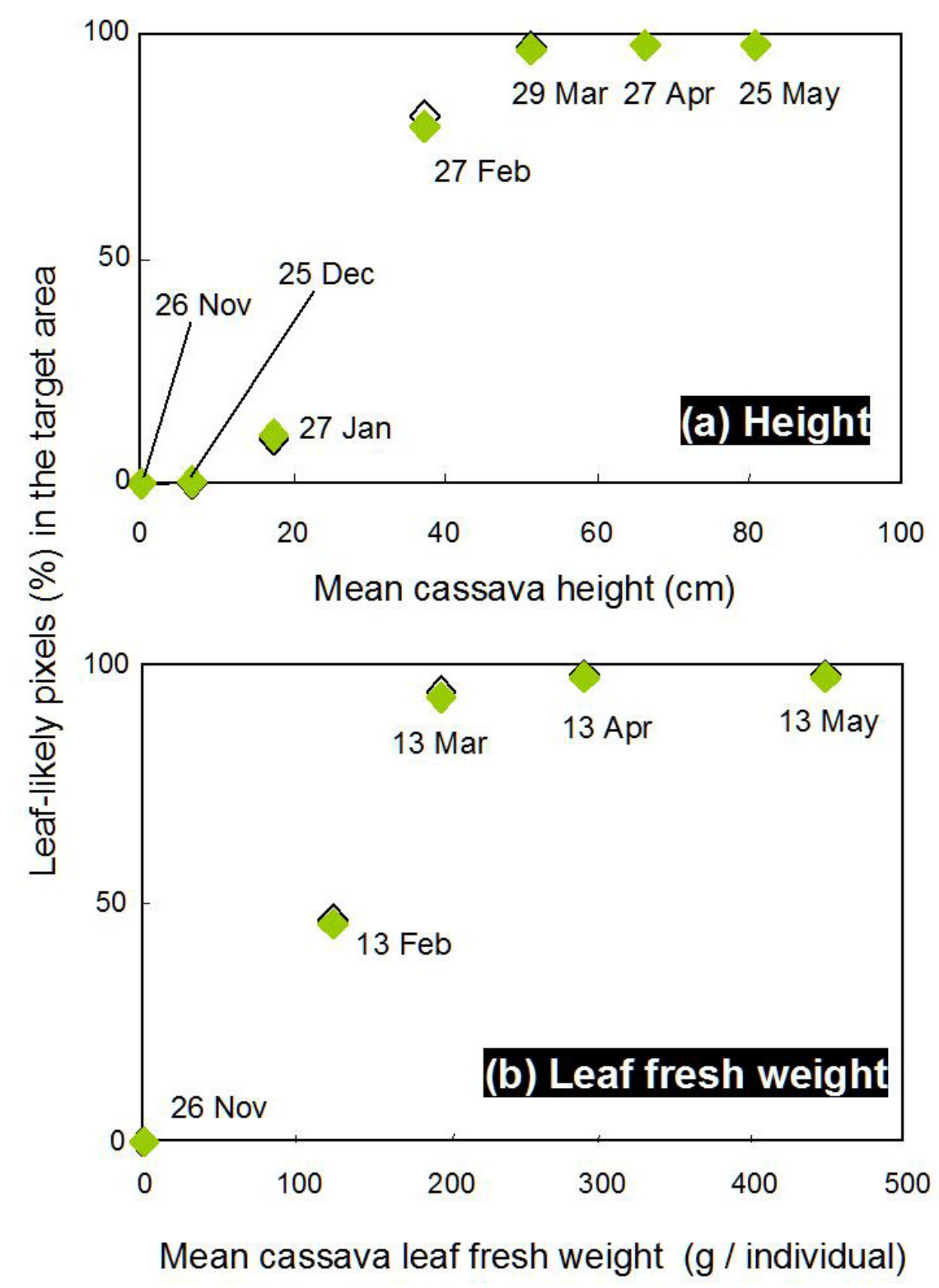

Fig. 5. Relationships between cassava height (a) and cassava leaf weight (b) and changes in leaf-likely pixels' percentage for the target area based on the R / G $(\diamond)$ and the $a^{*}(\diamond)$ grayscale images

Today, digital cameras and various types of software for digital photograph processing/analysis are quite commonly available. As such, the current method enables the discrimination between leaves and other objects by simultaneous binarization of multiple digital photographs multi-temporally acquired under different brightness levels. In this context, other related gadgets such as balloons may offer practical alternatives for the consecutive quantification of leaf area in agricultural fields and other areas (Verhoeven, 2009; Zhang \& Kovacs, 2012). Thus, the use of $\mathrm{R} / \mathrm{G}$ and $a^{*}$ as the indices for the determination of plant leaf area is worthy of consideration. 


\section{Acknowledgments}

The authors acknowledges the financial support by the Japan Society for the Promotion of Science (grant-in-aid 23255014).

\section{References}

Adobe Systems. (2002). Adobe Photoshop 7.0 Classroom in a Book. Adobe Press Inc., San Jose, CA. Adobe Photoshop 7. 0 Classroom in a Book.

Alves, A. A., \& Setter, T. L. (2000). Response of cassava to water deficit: Leaf area growth and abscisic acid. Crop Sci., 40, 131-137. http://dx.doi.org/10.2135/cropsci2000.401131x

Alves, A. A. C., \& Setter, T. L. (2004). Response of cassava leaf area expansion to water deficit: Cell proliferation, cell expansion and delayed development. Ann. Bot., 94, 605-613. http://dx.doi.org/10.1093/aob/mch179

de Martonne, E. (1926). Areism and aridity index. Comptes Rendus Hebdomadaires Des Seances De L Academie Des Sciences, 182, 1395-1398.

Doi, R. (2012). Simple luminosity normalization of greenness, yellowness and redness/greenness for comparison of leaf spectral profiles in multi-temporally acquired remote sensing images. J. Biosci., 37, 723-730. http://dx.doi.org/10.1007/s12038-012-9241-3

Doi, R. (2013). Discriminating crop and other canopies by overlapping binary image layers. Opt. Eng., 52, 020502. http://dx.doi.org/10.1117/1.OE.52.2.020502

Doi, R. (2014, in press). Red-and-green-based pseudo-RGB color models for the comparison of digital images acquired under different brightness levels. J Modern Opt. http://dx.doi.org/10.1080/09500340.2014.935506

Doi, R., Arif, C., Setiawan, B., \& Mizoguchi, M. (2013). Quantitative use of luminosity-normalized grayscale images of greenness, redness and yellowness of a rice canopy derived from multi-temporally acquired digital photographs. Int. J. Agric. Biol., http://www.fspublishers.org/published_papers/91820_.pdf

Doi, R., \& Ranamukhaarachchi, S. L. (2009a). Community-level physiological profiling in monitoring rehabilitative effects of Acacia auriculiformis plantation on degraded land in Sakaerat, Thailand. Silva Fenn., 43, 739-754. http://www.metla.fi/silvafennica/full/sf43/sf435739.pdf

Doi, R., \& Ranamukhaarachchi, S. L. (2009b). Correlations between soil microbial and physicochemical variations in a rice paddy: Implications for assessing soil health. J. Biosci., 34, 969-976. http://dx.doi.org/10.1007/s12038-009-0111-6

Doi, R., \& Ranamukhaarachchi, S. L. (2013). Slow restoration of soil microbial functions in an Acacia plantation established on degraded land in Thailand. Int. J. Environ. Sci. Technol., 10, 623-634. http://dx.doi.org/10.1007/s13762-012-0165-0

Gitelson, A. A., Kaufman, Y. J., \& Merzlyak, M. N. (1996). Use of a green channel in remote sensing of global vegetation from EOS-MODIS. Remote Sens. Environ., 58, 289-298.

Gray, V. M. (2000). A comparison of two approaches for modelling cassava (Manihot esculenta Crantz.) crop growth. Ann. Bot., 85, 77-90. http://dx.doi.org/10.1006/anbo.1999.0999

Handschuh, S., Schwaha, T., \& Metscher, B. (2010). Showing their true colors: A practical approach to volume rendering from serial sections. BMC Dev. Biol., 10, 41. http://dx.doi.org/10.1186/1471-213X-10-41

Heege, H. J., Reusch, S., \& Thiessen, E. (2008). Prospects and results for optical systems for site-specific on-the-go control of nitrogen-top-dressing in Germany. Precision Agriculture, 9, $115-131$. http://dx.doi.org/10.1007/s11119-008-9055-3

Jordan, C. F. (1969). Derivation of leaf-area index from quality of light on the forest floor. Ecology, $663-666$. http://dx.doi.org/10.2307/1936256

Köppen, W. P. (1931). Grundriss der klimakunde.

Lakio, S., Heinamaki, J., \& Yliruusi, J. (2010). Colorful drying. Aaps Pharmscitech, 11, $46-53$. http://dx.doi.org/10.1208/s12249-009-9351-x

Moriizumi, M., Nakashima, S., Okumura, S., \& Yamanoi, Y. (2009). Color-change processes of a plinian pumice and experimental constraints of color-change kinetics in air of an obsidian. Bulletin of Volcanology, 71, 1-13. 
http://dx.doi.org/10.1007/s00445-008-0202-5

Olthof, I., King, D. J., \& Lautenschlager, R. (2003). Overstory and understory leaf area index as indicators of forest response to ice storm damage. Ecol. Ind., 3, 49-64. http://dx.doi.org/10.1016/S1470-160X(03)00010-4

Pettorelli, N. (2013). The Normalized Difference Vegetation Index, Oxford University Press.

Uhart, S. A., \& Andrade, F. H. (1995). Nitrogen deficiency in maize: I. Effects on crop growth, development, dry matter partitioning, and kernel set. Crop Sci., 35, 1376-1383. http://dx.doi.org/10.2135/cropsci1995.0011183X003500050020x

Verhoeven, G. J. J. (2009). Providing an Archaeological Bird's-eye View - an Overall Picture of Ground-based Means to Execute Low-altitude Aerial Photography (LAAP) in Archaeology. Archaeological Prospection, 16, 233-249. http://dx.doi.org/10.1002/arp.354

Yang, Z., Willis, P., \& Mueller, R. (2008). Impact of band-ratio enhanced AWIFS image to crop classification $\begin{array}{lllll}\text { accuracy. Proc. } & \text { Pecora, } & \text { Retrieved }\end{array}$ http://www.asprs.org/a/publications/proceedings/pecora17/0041.pdf

Zhang, C., \& Kovacs, J. M. (2012). The application of small unmanned aerial systems for precision agriculture: A review. Precision Agriculture, 13, 693-712. http://dx.doi.org/10.1007/s11119-012-9274-5

Zheng, L., Shi, D., \& Zhang, J. (2010). Segmentation of green vegetation of crop canopy images based on mean shift and fisher linear discriminant. Pattern Recog. Lett., 31, 920-925. http://dx.doi.org/10.1016/j.patrec.2010.01.016

\section{Copyrights}

Copyright for this article is retained by the author(s), with first publication rights granted to the journal.

This is an open-access article distributed under the terms and conditions of the Creative Commons Attribution license (http://creativecommons.org/licenses/by/3.0/). 